\title{
PRESENTACIÓN DE LAS EDICIONES 6 Y 7 DE LA REVISTA JURÍDICA BIOLEX
}

\author{
Por: Héctor Rodríguez Espinoza ${ }^{1}$
}

En el marco de los festejos del LX Aniversario del Departamento de Derecho, en el Aula Magna "Roberto Reynoso Dávila" se presentaron las ediciones 6 y 7 de la Revista Jurídica Biolex. De los presentadores invitados, ${ }^{2}$ el Doctor Héctor Rodríguez Espinoza justificando la ausencia de sus pares, expuso a nombre de los tres lo siguiente:

Maestra Adelina Galindo Romero, Jefa del Departamento de Derecho. Colegas Doctoras. Adria Velia González Beltrones y Guadalupe Aleida Valenzuela Miranda.

Compañeros maestros y alumnos de nuestro Departamento.

Me place presentar esta Revista, fruto innegable del esfuerzo callado -pero por ello valioso- de la Academia de Derecho Administrativo y de los integrantes de los Cuerpos en Consolidación, "Derecho, Participación Ciudadana, Anticorrupción, Educación y Desarrollo Humano Comunitario e Institucional" y "Retos Actuales de las Ciencias Jurídicas y Sociales, ámbitos los primeros mencionados a los que me honro en pertenecer.

Resultaría ocioso -pero no lo es- insistir en que la calidad en la Filosofía, Misión y Visión de nuestro Departamento de Derecho ha dependido, depende y seguirá dependiendo siempre del trabajo de sus Academias, no sólo en la docencia en aulas, sino en labores de investigación en cubículos y bibliotecas y su divulgación en órganos académicos pertinentes como éste.

1 Profesor-investigador del Departamento de Derecho DCS Universidad de Sonora URC

${ }^{2}$ Blanca Valenzuela profesora Investigadora del Departamento de Psicología y Ciencias de la Comunicación de la Universidad de Sonora y Fernando Ribeiro Goncalves, Profesor Investigador de la Universidad do Algarve, Portugal. 
Y en este punto cabe apuntar en palabras de mis Colegas Blanca y Fernando "que las universidades deben intensificar esfuerzos que involucren a sus profesores y estudiantes en dimensionar su cultura institucional, además de no permanecer aisladas de la sociedad civil; por lo que uno de los aspectos contribuyentes hacia la motivación académica para docentes y estudiantes, seguramente lo será la factibilidad de compartir con la comunidad global-- al publicar-- el resultado de sus investigaciones y/o reflexiones en relación a las diferentes temáticas del quehacer jurídico, económico, político y social, en un medio electrónico e impreso, como lo es la Revista BIOLEX, ----cuya edición en versión impresa 6 y 7 está ya en manos del público que hoy nos acompaña.La consecuencia de que se involucren como colaboradores, será sentirse "dueños" y "responsables" del medio y de su propia trayectoria académica en el proceso de construcción de la cultura de la participación en el desarrollo de su entorno."

Ahora, bien, como saben, soy afecto a la colaboración en Revistas jurídicas y su dirección en nuestro medio, pues he dirigido las de la entonces Escuela de Derecho, la de la Comisión Estatal de Derechos Humanos y la del Tribunal Estatal Electoral. Me consta, por ello, la laboriosidad silenciosa y hasta incomprendida de participar en su conformación y, sobre todo, en el ensamble de colaboraciones de nuestros pares, sea un tema único o heterogéneo.

Debo referirme a la incipiente tradición de promoción, investigación y difusión de la cultura jurídica en nuestro Departamento -a pesar de sus 60 años de existencia- y en los homólogos en los recintos fraternos en Nogales, Caborca y Navojoa.

Buceo en mi biblioteca particular, escojo y traigo conmigo para mostrar a ustedes, ejemplares de las Revistas que, desde los lejanos 50s, aportaron el extinto Colegio Sonorense de Abogados A. C. (antecesor de nuestra Barra Sonorense de Abogados A. C. Colegio) y la Universidad de Sonora. Sólo les leeré los títulos de los artículos y sus autores, la gran mayoría de éstos, ex catedráticos de nuestro Departamento, pero que se nos han adelantado en el 
camino sin retorno. En todo caso debemos evitar que se siga acumulando el injusto polvo del olvido sobre su memoria, sobre nuestra memoria.Su recopilación, valoración crítica y divulgación es una preciosa línea de investigación que nos está esperando en nuestra completa Biblioteca. Nos están llamando con sus brazos abiertos.

Esta Revista, en particular, contiene artículos de vanguardia de autores jóvenes la mayoría, dignos de leerse y replicar en clase con nuestros grupos de alumnos, para que sembremos en ellos, cual campo fértil, la fecunda semilla de la investigación, para que nuestra filosofía y ciencia avancen.

Muy importante de este logro editorial es que recientemente se obtuvo del Instituto Nacional del Derecho de Autor INDAUTOR, el ISSN (International Standard Serial Number / Número Internacional Normalizado de Publicaciones Seriadas) que es un código numérico reconocido internacionalmente para la identificación de las publicaciones seriadas. EI ISSN puede utilizarse siempre que haya que recoger o comunicar información referente a las publicaciones seriadas, evitando el trabajo y posibles errores de transcribir el título o la información bibliográfica pertinente. EI ISSN identifica sin ambigüedades ni errores la publicación seriada a la que va asociado. Es el equivalente para las publicaciones seriadas de lo que es el ISBN para los libros. Sólo observaría que demos un siguiente paso: de acuerdo con los cánones editoriales, que la convirtamos, de una Revista folleto, en una Revista libro, es decir que tenga más de 100 páginas y lomo, para su fácil identificación en los estantes de las bibliotecas. ¿Qué es más onerosa?, por supuesto, pero para eso está la capacidad de gestión de recursos ante la administración central y, como lo hacían los directores de las Revistas que he citado al principio: buscar y obtener patrocinio privado y social en las fuentes, cuyos egresados deben guardar un mínimo sentimiento de gratitud hacia nuestro Departamento, que les cambió su vida.

Muchas Gracias 